\title{
RESEARCH PAPER \\ STUDENTS' AWARENESS OF AND ADHERENCE TO ENERGY MANAGEMENT PRACTICES IN SELECTED STUDENTS' HALLS OF RESIDENCE AT KWAME NKRUMAH UNIVERSITY OF SCIENCE AND TECHNOLOGY, GHANA
}

\author{
S. Amos-Abanyie ${ }^{1}$, E. T. Kwofie ${ }^{2}$ and E. S. Asare ${ }^{3}$ \\ ${ }^{1,2,3}$ Department of Architecture, College of Art and Built Environment, \\ KNUST, Kumasi
}

\begin{abstract}
Energy management is one of the current policy directions of the Ghana government given the increasing challenges associated with energy generation to cope with the growing demand. A conscious attempt at adopting practices aimed at conserving energy is considered a sinequanon to coping with the current energy challenges in Ghana. However, an assessment of the awareness level of energy management practices is yet to be rigorously pursued as an agenda towards energy conservation in institutions and agencies perceived to be high energy consumers. Currently, the increasing growth in student numbers in the universities in Ghana and the high energy demands against the low level of energy generation to cope with these demands needs urgent attention. Consequently, adherence to effective energy management practices among students in these universities is considered a prima-facie in coping with the energy challenges in the country. The aim of this study was to assess the awareness and adherence levels of energy management practices of students in tertiary institutions in Ghana. Using KNUST as a case study, a questionnaire survey was carried out amongst students in residential accommodation on the campus. Subsequently, mean score and one sample t-test analyses were employed to analyze the empirical data elicited. The findings revealed a generally low awareness and adherence level to the critical energy management practices amongst students. These findings have implications for energy policy formulation and innovations towards conservation and management.
\end{abstract}

Keywords: Energy management, Ghana, Hostels, Students

\section{INTRODUCTION}

The current energy crisis being experienced in Ghana has drawn attention to several concepts, approaches and innovations aimed at curtailing this national crisis. In recent times, one of such attempts on the agenda of the government to resolve the energy crisis is conscious and continued efforts to conserve and manage energy consumption by the population. Inadequate effort by successive governments to lay down 


\section{Amos-Abanyie et al.}

pragmatic and strategic plans to ensure reliable electricity supply in the country as well as the general public's attitude towards energy saving accounts for these developments (Osei, 2012). Some stakeholders see efficient management and utilization of available energy as the sure way to reduce the continued energy wastage in the country.

According to Amewode (2010), about $30 \%$ of the energy produced in Ghana is wasted and this poses a hindrance to economic growth. Periodic upward review of electricity tariffs has been adopted as a mechanism to sustain electricity generation and supply in Ghana in recent years. However, users of electricity are yet to experience a steady supply as there has been constant and continuous disruptions in energy supply, leading to planned and unplanned load shedding programmes. Achieving a steady supply of electricity is very important for all institutions and establishments especially the universities because of their peculiar nature as knowledge based institutions with the predominant energy source being electricity (Unachukwu, 2010). The above makes the continuous and stable supply of electricity in the universities for academic, social and economic activities imperative.

Ghana has a number of tertiary institutions including public universities, polytechnics, colleges of education that are run on government subvention and thus cannot remain unconcerned and detached from the global and national drive to reduce energy wastage and conservation (Unachukwu, 2010). The bulk of the electricity generated in Ghana, forming about $73 \%$ is consumed by households and institutions (ECG, 2006; Arko, 2013). This indicates that adherence to energy management will greatly reduce wastage in energy use (Imani Ghana, 2014). Despite efforts by various governments and stakeholders to conscientize the public on the importance and benefits of the efficient use of energy, a walk through the students' halls of residence and hostels on the campuses of several public tertiary institutions including universities and polytechnics reveal students' poor attitude towards energy saving and conservation. These developments call for a paradigm shift in the attitudes of students towards energy conservation and waste reduction. The attitude of students could plausibly be attributed to lack of knowledge in energy management practices or deliberate attempt to ignore the adherence of these practices due to lack of enforcement or monitoring.

This study has been undertaken with the aim of assessing the level of awareness and adherence to energy management practices among students in the Kwame Nkrumah University of Science and Technology (KNUST). The relevance of this study is premised on the fact that raising the awareness and adherence level of energy management concepts and practices among students will undoubtedly lead to significant reduction in energy wastage on the campus and contribute to the broader national energy management agenda. This is because students' awareness and adherence to efficient energy management practices cannot be ignored if the universities and colleges are to improve upon their overall energy wastage reduction and consumption cost.

\section{Energy management concepts}

The Carbon Trust (2011) defines energy management as the systematic use of management techniques, practices and technology to improve an organization's energy consumption and performance. Capehart et al. (2003) also defined energy management as the cautious and effective use of energy to capitalise on profits and to improve competitive positions. The Carbon Trust (2011) asserts that, energy management must be proactive, energy efficient and consider linking energy management with energy efficiency either in generation or usage. Hence it can be said that, the core objectives of energy management are to reduce cost and wastage which are achieved through energy efficient practices among the users of the energy. Energy management activities could range from relatively inexpensive and easily 
implementable actions referred to as "low hanging fruits" such as turning off lights and switches when not in use to expensive technology such as using electric sub-meters to monitor and improve consumption. It is advisable to work on the easier actions and use the benefits accrued to continue with higher levels until policy targets, objectives and goals are attained and the gains are sustained and improved (Capehart et al., 2003).

The adoption and enforcement of energy management practices at the national level in Ghana was able to save an amount of $\$ 300,000,000.00$ through an intensive energy awareness creation exercise (ECG, 2006; Amewode, 2010). Amongst the measures that contributed to energy conservation by the government was the enactment of a legislation that helped prevent the country from becoming a dumping ground for inefficient machinery (Amewode, 2010). This legislation included the introduction of appliance standards and labelling in the form of a sticker. Another exercise was the replacement of incandescent bulbs throughout the nation. Under this exercise, five million pieces of incandescent bulbs of various wattages ranging from $40 \mathrm{~W}$ to $100 \mathrm{~W}$ that consume a total of about $581 \mathrm{GW}$ of electricity per annum were swapped with six million pieces of compact fluorescent lamps (CFL) in the range of $9 \mathrm{~W}$ to $20 \mathrm{~W}$ that consume a total of about $151.475 \mathrm{GWH}$ of electricity annually (Amewode, 2010).Unfortunately, this could not be sustained and has consequently led to increase in energy wastage in recent times contributing to the current energy crisis in the country (Imani Ghana, 2014). The inability to sustain such programmes has largely been attributed to lack of commitment from successive governments who often want to be credited with new programmes implemented in their era (Imani Ghana, 2014). Additionally, Amewode (2010) revealed that, the inability of successive governments to make significant capital investment in the energy sector in generation and equipment replacement have largely been the contributing factor to the current energy crisis in Ghana.

Awareness and Adherence to Energy Management Practices Several studies have identified awareness creation as a significant factor that facilitates a successful energy conservation intervention (Wai et al., 2006). Despite the wide knowledge on the significance of energy awareness, most managers, having limited understanding and appreciation of their potential, pay little or no attention to the benefits of raising energy awareness and they tend to be sceptical of behavioural change strategies, thus leading to energy inefficiency, loss of revenue and other consequences such as environmental degradation (Brew-Hammond and Kemausuor, 2007; Wai et al., 2006).

According to Wai et al. (2006), adherence to a concept such as energy saving depends on a number of complex factors. These include extrinsic motivators such as pricing and reward systems and intrinsic or self-induced motivation arising from receiving and paying attention to information. The later may lead to a comprehension and in the process a transformation of one's beliefs and attitudes which could finally lead to a motivation to change to a compliant behaviour. Extrinsic factors such as large investments in technology and reward systems for motivation are known to be less effective and unsustainable (Wai et al., 2006). In testing a model devoid of extrinsic measures such as reward systems or punitive measures in an Australian context, researchers demonstrated that student involvement and 'buy-in' to the concepts of energy conservation, using strategies that foster energy reduction as a social norm were important and effective and recommended that any energy saving programme should foster student involvement at all stages of development and monitoring (Black et al., 2009).

A study by Petersen et al. (2007) identified three factors necessary for influencing energy conservation as knowledge, motivation and control (concern) and capacity and physical condition" that stimulate energy conservation 
practices of individuals. Petersen et al. (2007) compared different residential setting of dormitories amongst a group who pay a fixed amount irrespective of their consumption patterns and another who pay according to the energy consumed. It was demonstrated that knowledge and concern for environmental factors provided sufficient motivation for adherence to improved energy management practices. A combination of motivational packages including competitions among the dormitories improved energy conservation practices. Some practices such as turning off lights when not in use were popular and were reported as being practiced prior to the competitions (Peterson et al., 2007).

Black et al. (2009) conducted energy usage assessment involving the installation of a digital display device that provided instant feedback on electricity consumption level. By following extensive studies, social marketing campaigns, consistent patterns of lower energy consumption (both gas and electricity) in the intervention groups compared to the control were realized. Differences in reduction in electricity varied from $17 \%$ to $28 \%$; and from no decrease initially, to a decrease of $19-34 \%$ in the gas consumption in intervention versus the control group. The authors concluded that the provision of real-time feedback display (using the ecoMeters) together with social marketing support strategies significantly influenced energy consumption behaviours and enhanced inherent motivation. Also the students appreciated and were motivated by the supportive environment of the University, in attending promptly to maintenance of faulty infrastructure and appliances demonstrating that the authorities' prioritized attention of energy management.

A conceptual framework of energy awareness development process developed by Wai et al. (2006), cited two main energy conservation methods; 1) Technology fixed and 2) Behavioural approaches. Technology fixed involves the use of instruments such as motion sensor controls and photovoltaic; whiles behavioural approach requires changes in human attitude through motivation, awareness raising and skills development. They conclude that both methods are practical and can be applied together. In this study awareness and adherence to specified energy management practices were measured and presented. Adherence measurement approaches such as reported behaviour / practices, and more empirical ways such as observing behaviours have proven to be effective in facilitating changed energy consumption behaviours in earlier studies on energy management (Wai et al., 2006; Black et al., 2009 and Environmental Protection Agency New England US (EPA), 2007) were adopted for this study. A deductive approach was employed for this study since the research was derived from a particular set of parameters (Creswell, 2009).

\section{METHODOLOGY}

The study was carried out in KNUST and the empirical data was collected through a questionnaire survey. Twenty three critical energy management practices developed by the Energy Foundation (2005) were adopted for the design of the questionnaire. Out of the total eight (8) halls on campus, three were selected and the structured questionnaires were administered on sampled students in the selected halls of residence at KNUST to assess their level of awareness of these practices and to what extent they adhered to them. The questionnaire had two sections. The first section encompassed personal information of respondents which included their halls of residence and year of study. The second section related to the objective of this research which was to examine the awareness and adherence levels of the energy management practices of students in the selected hall of residence.

The respondents answered the questions based on a five-point likert scale rating with five being the highest of the rating and interpreted as $1=$ Totally Unaware (Not Very Often), $2=$ Slightly Aware (Not Often), 3= Averagely Aware (Neutral), 4=Aware (Often), and 5= Very Much Aware (Very Often). The interpret- 
tation in the brackets is for the measure of adherence level. By adopting a purposive sampling, three halls of residence were selected: the Chancellor's Hall (mixed hall), the University Hall (male only) and the Queen Elizabeth II Hall (mixed hall). In administering the questionnaires to the respondents in the selected halls, a random sampling technique was adopted in each of the selected halls of residence. The adoption of the random sampling technique was influenced by its characteristic of being suitable for avoiding bias often associated with other sampling techniques (Creswell, 2009).

At the end of the survey over a four week period from 15th March to 14th April, 2014, 150 questionnaires were retrieved out of a total of 243 that were distributed to sampled students in the three selected halls of residence representing $62 \%$ response rate. From this total number of students, 50 were in University hall, 49 in Queen's hall and 51 from the Chancellor's hall. The distribution of selected students amongst the halls of residence studied and their year of study is presented in Table 1 . Out of 150 students who responded to the questionnaire, 98 (representing 65.3\%) were male and 52 (representing $34.7 \%$ ) were female. The male dominance is attributed to the fact that University Hall is a male-only hall. The number of respondents in the first year was 85 (representing $56.7 \%$ ) of the respondents. A total of seven (representing 4.7\%) students were in second year, nine students representing $6.0 \%$ in the third year and the fourth years formed $32.7 \%$ of the respondents. These findings are due to the fact that the questionnaires were randomly distributed; hence it is a fair representation of the student population resident on campus and in the selected halls of study. Also, the dominant representation of first year students is due to the residential policy that makes first years enjoy residence status as a priority. The data collected were analyzed with the Statistical Package for Social Sciences (SPSS) Version 19 using mean score and one sample t-test.

\section{RESULTS AND DISCUSSIONS}

Mean score and one-sample t-test are useful in determining whether the population considered a specific attribute to be important or otherwise by giving a picture of the consensus reached by the respondents in an empirical survey (Motulsky, 2005; Field, 2009). A summary of the mean scores and test results is shown in Table 2. The mean for each attribute including the associated standard deviation and standard error are also reported. In assessing the significance of the level of agreement reached on attribute of the management practices, the null hypothesis formulated was that for each of the attributes, the level of awareness and adherence was unacceptable $\left(\mathrm{H}_{0}: \mathrm{U}=\mathrm{U}_{0}\right)$ and the alternative hypothesis was that the attribute's

Table 1: Distribution of students with respect to the halls of residence and year of study

\begin{tabular}{|c|c|c|c|c|c|c|c|c|c|c|}
\hline Halls & $\begin{array}{l}\text { Uni } \\
\text { Hal }\end{array}$ & sity & $\mathbf{Q u}$ & Hall & $\begin{array}{l}\text { Cha } \\
\text { Hal }\end{array}$ & ellor's & Tota & & Sex & \\
\hline Sample & No. & $\%$ & No. & $\%$ & No. & $\%$ & No. & $\%$ & Male & Female \\
\hline $1^{\text {st }}$ Year & 46 & 90 & 39 & 80 & 0 & 0 & 85 & 56.7 & 56 & 29 \\
\hline $2^{\text {nd }}$ Year & 0 & 0 & 3 & 6 & 4 & 8 & 7 & 4.7 & 5 & 2 \\
\hline $3^{\text {rd }}$ Year & 1 & 2 & 1 & 2 & 7 & 14 & 9 & 6.0 & 6 & 3 \\
\hline $4^{\text {th }}$ Year & 3 & 8 & 6 & 12 & 40 & 78 & 49 & 32.7 & 32 & 17 \\
\hline Total & 50 & 100 & 49 & 100 & 51 & 100 & 150 & 100 & $98(65.3 \%)$ & $52(34.7 \%)$ \\
\hline
\end{tabular}




\section{Amos-Abanyie et al.}

level of adherence and awareness was acceptable $\left(\mathrm{Ha}: \mathrm{U}>\mathrm{U}_{0}\right)$, where $\mathrm{U}_{0}$ is the population mean $\left(\mathrm{U}_{0}\right.$ was fixed at 3.5 , drawing on conventional criteria for testing significance as reported in Ling, 2003). Here, the significance level was set at conventional $95 \%$ in most built environment and social research (Motulsky, 2005). Hence, from the five-point Likert rating scale, an acceptable level of adherence and awareness on the energy management practice attributes was deemed acceptable if it had a mean of 3.5 or more. Generally, the characteristics of the data (mean scores, standard deviation and standard mean error) are examined towards how representative the sample is to the population as well as the variability and consistencies in the responses. From the results presented in Table 1, 38 of the standard deviations associated with the mean scores (awareness level (13) and adherence level (20)) realized were greater than 1.000 .

According to Field (2009), a standard deviation greater than 1.00 is considered very large and consequently suggests that there is large variability in the data and low level consistency in agreement among the respondents. Likewise, the standard mean error of sampled data refers to the measure of how representative a sample is to the population and thus a large standard error (relative to the sample mean) suggests that there is a lot of variability between means of different samples whereas a small standard error suggests that most sample means are similar to the population mean and so the sample is likely to be an accurate reflection of the population (Motulsky, 2005). The results in Table 2 indicate that the standard error associated with all the means were relatively close to zero suggesting that the sample chosen is an accurate reflection of the population (Motulsky, 2005). Additionally, the findings as demonstrated by the p-values (two-tailed, $\mathrm{U}<\mathrm{Uo}$ ) (t-test) indicate that the mean values for most of the variables especially the high energy consuming gadgets were statistically insignificant.

The summary of results of the mean scores empirically suggests that generally, the mean scores associated with the energy management practices variables were less than the acceptable cut-off value of 3.5 . This suggests that the awareness and adherence level of students on these energy management practices are at unacceptable levels among the student body. This is because for an awareness and adherence level to be considered acceptable, the mean score must be greater than 3.5. A critical assessment of the findings gives varied revelations. It is very interesting to observe from the results that though on some of the variables, even though the awareness level was satisfactory and acceptable, students failed to adhere to their practice. For example, 'Switching off lights when sleeping' and 'Iron garments in bulk' which recorded acceptable mean score levels of awareness of 3.66 and 3.55, while the adherence among the student body was of unacceptably low means of 3.05 and 2.35 respectively.

Against the background that awareness and adherence to the energy management practices has now been recognized as an important energy management policy direction to curtail energy crisis in Ghana (Brew-Hammond and Kemausuor, 2007), an empirical evidence of the performance of the level of awareness and adherence to key management practice is crucial in current and future decisions (Wai et al., 2006). Empirical evidence is also considered very critical in assessing the effectiveness of the energy management concepts adopted and implemented (Wai et al., 2006; Black et al., 2009). The generic assessment of the level of awareness and adherence to the energy management practices among students at KNUST (Table 2) reveals both expected and unexpected results. The overall assessment of the awareness level of the energy management practices reveal that, generally, students show very weak level of awareness as well as on key practices that are deemed to be high energy consuming. This is supported by the overall awareness level mean score of 2.61. Surprisingly, students generally show an acceptable level of awareness with mean scores greater than 3.0 on five 
Energy management practices of students at KNUST... 102

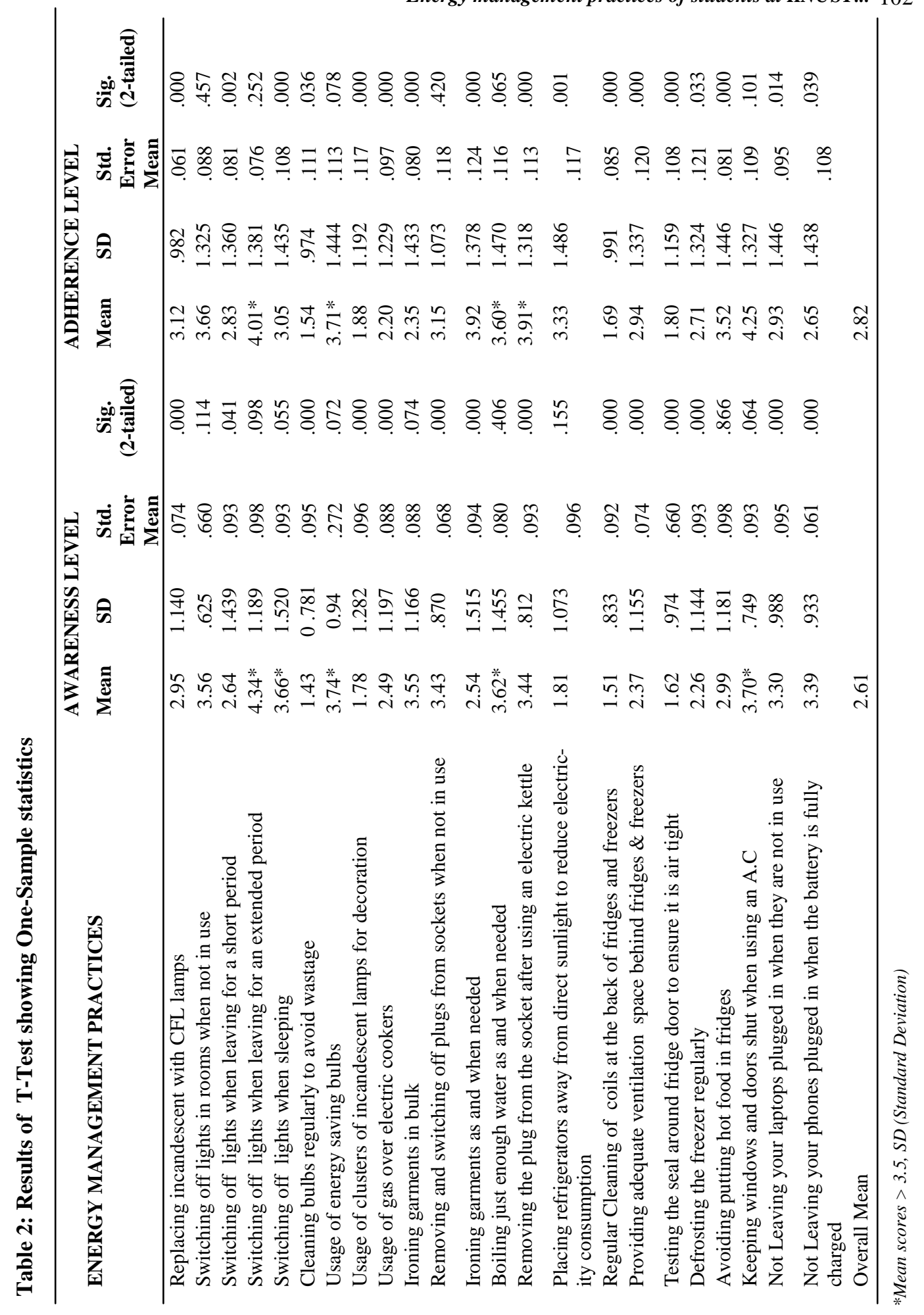


(5) out of the total of twenty three (23) practices.

The results also suggest that majority of the students are aware of the need to replace incandescent bulbs with compact energy saving fluorescent lamps'. This is a good result, as it confirms the effectiveness of the efforts to replace all incandescent bulbs with compact florescent lamps contained in a policy intervention by the government some few years ago. Additionally, though certain energy management practices such as 'switching off light when not in use' have been proven to be effective in facilitating changed energy consumption behaviours as cited in studies on energy management interventions carried out in several countries by Wai et. al. (2006) and Black et al. (2009). Table 2 further reveals that some of the recently acknowledged new and emerging practices are not well adhered to among the students. This is because, the results revealed that the majority of the students sampled are not very much aware of these energy management practices regarded as being rudimentary whiles their corresponding adherence level also fell below the acceptable levels as seen in the predominant mean scores of these practices being below 3.5. Examples can be cited as 'replacing incandescent with CFL lamps' (2.95 and 3.12), 'switching off lights when leaving for a short period' (2.64 and 2.83) (see Table 2) etc.

Several studies have identified energy awareness as a significant factor that facilitates a successful energy management and conservation intervention (Vasma, 2002; Wong, 1997; Wai et al., 2006). According to Wai et al. (2006), awareness creation is one of the most significant and effective means of encouraging energy savings amongst individuals in organizations such as employee in a work place and students. Wai et al. (2006) revealed that awareness and understanding of basic energy conservation and management practices such as switching off gadgets not in use and use of energy efficient lights and gadgets are effective in making significant gains. Unfortunately, in this study, the worrying observation is that, students seem to show low or limited awareness level on practices that are practically deemed to be high energy consuming such as 'ironing garments in bulk' and 'Usage of gas over electric cookers'.

Empirically, Pancucci (1998) revealed that raising staff and student awareness of energy conservation management are effective when implemented as strategic policy towards energy efficiency and environmental protection and thus continuous education and wide knowledge on the significance of energy management awareness is critical.

Additionally, it is worth noting that whilst energy management practices related to the use of air conditioners, refrigeration and other high energy charging items are deemed to have health and safety implications which tertiary education authorities critically want to control and enforce, the emergence of poor energy management awareness and adherence level among the students offers increased and heightened consequential risks and danger in these students' halls of residence. In several reported news in the Ghanaian media, many fire outbreaks are attributed to the use of such gadgets (Ghana News Agency, 2013). The results also indicate that, the use of fridges and freezers and air conditioners were unacceptable in their mean scores. The findings further suggest that the students are totally unaware of the fact that refrigerators must be kept away from direct sunlight, with the coils being cleaned regularly and the fridge door requires testing to ensure that they are air tight. Ultimately, the findings revealed that students also exhibited poor level of adherence to these high risk related practices. Given these risks and likely antecedent dangers, it is not understandable that students do not take these practices seriously. Surprisingly, the results further revealed that on some practice, the students showed acceptable level of awareness with mean scores being greater than 3.5 such as 'switching off lights when sleeping' (see Table 2). Unfortunately, the level of adherence on such practices was very poor. 
Additionally, with the results also suggesting the students having acceptable level of awareness but not being able to adhere and practice could possibly be due to the lack of enough stimuli to be self-motivated to make a positive behavioural change (Wai et al., 2006).

Based on the energy consumption unit ratings in Ghana, certain electrical gadgets such as electrical irons, air conditioners, electrical cookers, refrigerators, etc. are considered high energy consumption units. However, it is interesting to note that, whilst energy conservation practices on these gadgets are considered critical in mitigating the current energy crisis in the country, practicing these among the students is still below acceptable level. This suggests that the intense education by the Ministry of Energy and the Energy Foundation is yet to yield any results especially among tertiary students.

In respect of the level of adherence to the energy management practices, generally, the results indicated a weak overall adherence level mean score of 2.82 (see Table 2). Interestingly, students show an acceptable level of adherence (mean greater than 3.5) on just four (4) of the total of twenty three (23) practices. Unfortunately, students again show poor adherence level to energy management practices perceived as high energy consuming practices. Theoretically, this is not surprising given the observed weak awareness on these practices among the students. This is because, practically, people are more likely not to practice what they lack knowledge on. However, with the results revealing a rather poor adherence level to basic practices such as 'switching off lights when leaving for a short period', 'removing and switching off plugs from sockets when not in use' and 'defrosting the freezer regularly' could plausibly be more likely to be attributed to behavioural attitudes among students than lack of knowledge.

Practically, Wai et al. (2006) and Black et al. (2009) have proven that adherence to energy conservation and management practices is very effective in facilitating changed energy consumption behaviours and in attaining results in polices through behavioural change and the use of equipment to monitor energy consumption. Additionally, Black et al. (2009) revealed that adherence to a concept such as energy saving can be improved by extrinsic measures that can affect effective behavioural change (Black et al., 2009). Petersen, et al. (2007) identified an approach of making students responsible for directly paying for their energy consumption as an effective extrinsic measure that significantly influences behavioural change as well as being effective in influencing energy conservation. Perhaps from the practical perspective, allowing students to pay for their energy consumed could significantly improve the awareness level and adherence to energy conservation and management practices and must be pursued.

\section{IMPLICATIONS OF THE FINDINGS}

In Ghana, it is generally perceived that energy management and conservation have emerged as the immediate critical policy direction of government towards mitigating the periodic energy crisis over increased generation of power to offset demand deficit (Osei, 2012). The findings of this study offer plethora of implications for current national interventions in energy management practices and conservation as well as among the general consumers.

Noting that adherence to efficient energy management and conservation practice (EM and $\mathrm{CP})$ has a significant influence on the energy outcomes for use and generation to improve competitive positions (Capehart et al., 2003; Amewode, 2010 ; IEA, 2014; ISO, 2011), the insights given by this study could be useful to the development and adoption of effective strategies and interventions that can likely improve the current development. EM and CPs which have substantial potential to influence high levels of energy saving could be intensified as well as adopting effective strategies over existing interventions. The findings on the awareness and adherence levels of these practices could also provide the necessary stimulus 
authorities of tertiary institutions to re-invent their energy management policies towards good results inherent from attitudinal and behavioural change among the general student body. To this end, the findings could thus inform the adoption of direct monitoring, technological system, reward systems, re-aligning electrical wiring and installation designs towards increasing both awareness and adherence to potentially improve energy conservation among the students.

The insight into the findings which reveal the likely antecedent high risk safety and fire outbreaks especially related to high energy consumption gadgets could also be useful to decisions in safety planning and related electrical fires. The theoretical position of safety issues is more towards prevention than control inherent in behavioural change and compliance (Petersen et al., 2007). Hence, the findings revealed by this study offer the management of the university and facility managers an evidence-based justification for devising and implementing effective safety and risk control measures to mitigate the potential of the unacceptable adherence level of these energy management practices in the halls of residence. Given the electrical induced fire outbreak at Unity Hall on the KNUST Campus on $30^{\text {th }}$ July 2014 (Worgbah, 2014) as a lesson, such safety and risk control measures could be targeted at ensuring voluntary and involuntary compliance to efficient energy management and conservation practices and feedback towards improvement in energy saving and conservation.

\section{CONCLUSION}

In response to limited studies providing empirical evidence on energy management practices to inform policy interventions and sensitization in Ghana and other developing countries, this study adopted a questionnaire survey to assess the level of awareness and adherence to energy management practices among students of KNUST. The assessment indicates that, the level of awareness and adherence to energy management and conservation practices among students is below acceptable levels. Additionally, it is clearly evident that even though on some practices, students' level of awareness was acceptable, their adherence to same practices was weak suggesting that high level of awareness does not guarantee acceptable level of adherence in energy management practices among students. It further revealed that KNUST students residing on-campus generally have a low level of awareness and adherence to energy management practices particularly in relation to high energy consuming appliances.

In the light of this, the energy management practices in relation to the use of high energy consuming appliances are the critical practices that when addressed together with basic practices concerning the switching off lights, plugs and unplugging appliances when not in use will significantly lead to energy savings. In summary, this study has given an empirical support for the generally held perception of energy wastage and mismanagement among the student body in tertiary institutions in Ghana.

\section{REFERENCES}

Amewode, L. (2010). Ghana Makes \$300m Savings On Energy. Accessed from: http:// www.ghanaweb.com/GhanaHomePage/ NewsArchive/artikel.ph. on: 11/11/2013

Arko, C. (2013). Energy conservation, key to sustainable power use in Ghana. Accessed from: http://www.ghananewsagency.org/ features/energy-conservation-key-toEnergy conservation, key to sustainable power use in Ghana, on: 22/10/2013.

Black, R., Davidson , P. and Retra, K. (2009). Facilitating energy saving behaviours among University student residents reportnumber.53. Accessed from: http:// www.csu.edu.au/__data/as sets/ pdf_file/0006/702879/53_energy_saving_beh aviour.pdf. on: 15/03/2014.

Brew-Hammond, A. and Kemausuor, F. (2007). 
Energy Crisis in Ghana: Drought, Technology or Policy? Kumasi: Kwame Nkrumah University of Science and Technology (KNUST). Accessed from:http:// e n e r g y c e n t e r. kn u s t.e d u.g h/ downloads/8/81.pdf on 1/10/2013.

Capehart, B. L., Turner, W. C. and Kennedy, W. J. (2003). Guide to Energy Management (Fourth Edition ed.). The Fairmont Press, Lnc. . [Online] Accessed from: http:// sydneyhvac.net/Files/energyman/ GuidetoEnergyManagement.pdf on $10 / 1 / 2013$.

Carbon Trust. (2011). An introduction to energy management. Carbon Trust. Accessed from: http://www.carbontrust.com/ $\mathrm{m}$ e $\mathrm{d}$ i $\quad \mathrm{a} \quad / \quad 7 \quad 3 \quad 8 \quad 5 \quad /$ ctv045_an_introduction_to_energy_manage ment.pdf on 22/10/2013.

Creswell, J. W. (2009). Research design: qualitative, quantitative, and mixed method approaches. 3rd ed. California: Sage Publications.

Electricity Cooperation of Ghana (E.C.G). (2006). Strategic National Plan 2006 2020.Annes I of IV. Energy Demand Sectors of the Economy. Accessed from: http:// energycom.gov.gh/files/snep/MAIN\% 20REPORT\%20final\%20PD.pdf on 30/09/ 2013.

Energy Foundation, Ghana. (2005). Cost of Using Appliances Energy Foundation, Ghana. Accessed from: http:// www.ghanaef.org/energyinghana/ costofusingappliances.htm on 12/10/2013.

Environmental Protection Agency New England US (EPA). (2007). Best Energy Management Practices for Colleges. Accessed from: http://www.epa.gov/region1/assistance/ univ/pdfs/bmps/SCSUSubmetering 1-807pdf, on 21/10/2013.
Field, A. (2009). Discovering Statistics, Using SPSS for Windows, $3^{\text {rd }}$ Edition, Sage Publications, London.

Ghana News Agency. (2013). GSA Holds Seminar On Energy Management. Accessed from:http://www.ghananewsagency.org/ economics/gsa-holds-seminar-on-energymanagement- 63647 on 22/10/2013.

IEA. (2014). Progress Implementing the IEA 25 Energy Efficiency Policy Recommendations. International Energy Agency Accessed from: http://www.iea.org/publications/ insights/insight publications/ name,15211,en.html on 15/5/ 2014.

Imani Ghana. (2014). Price and Deregulation of the Energy Sector In Ghana: Challenges and Prospects. Imani Publication. Accessed from: http://www.imanighana.com/2014/01/ pricing-and-deregulation-of-the-energysector-in-ghana-challenges-prospects on 19/4/2014.

ISO. (2011). ISO 50001 energy management standard impacts the bottom line. Accessed from: http://www.iso.org/sites/ iso50001launch/index.html on 22/10/2013.

Ling Y. Y. (2003). A conceptual model for the selection of architects by project managers in Singapore. International Journal of Project Management: 21 (2):135-144.

Motulsky, H. J. (2005). Prism 4 Statistics Guide -Statistical analyses for laboratory and clinical researchers. GraphPad Software Inc., San Diego CA, 2003,

Osei, K. (2012). The electricity power outages uncovered - Don't blame the ECG. Modern Ghana. Accessed from: http:// www.modernghana.com/news/388698/1/theelectricity-power-outages-uncovered-dontblame.html on 30/9/2014.

Pancucci, D. (1998). Imperial College and En- 


\section{Amos-Abanyie et al.}

ergy Savings. Facilities Management. 5(3): $10-11$.

Petersen, J. E., Shunturov, V., Janda, K., Plat, T. G. and Weinberger, K. (2007). Dormitory residents reduce electricity consumption when exposed to real-time visual feedback and incentives. International Journal of Sustainability in Higher Education, 8 (1): 16-33. Accessed from: https://my.vanderbilt.edu/ c s $265 / \mathrm{fil}$ e s / 2010 / $11 /$ Lucid_IJSHE_DormEnergyFeedback.pdf on 28/9/2013.

Unachukwu, G. O. (2010). Energy savings opportunities at the University of Nigeria, Nsukka. Journal of Energy in Southern Africa. $21(1): 2-10$

Vesma, V. (2002). Power to the People Facilities Management. Facilities Management. 9 (5): $21-79$

Wai, C. W., Mohammed, A. H. and Alias, B.
(2006). Energy Conservation: A Conceptual Framework of Energy Awareness. Johor: University Technology Malaysia. Accessed from: http://eprints.utm.my/544/1/58-67.pdf on $15 / 3 / 2014$.

Wong, S. S. M. (1997). Energy Conservation and Human Behaviors: The Professional Faculties Building in the University of Calgary. University of Calgary: Master Degree Project.

Worbgah, C. (2014). Breaking News: Fire outbreak at Unity (Conti) Hall of KNUST. Accessed from: http://watsuptek.com/breakingnews-fire-outbreak-at-unity-hall-of-knust on $11 / 8 / 2014$.

Yik, F. W. H., Lee, W. L. and Ng, C. L. (2002). Building energy efficiency and the remuneration of operation and maintenance personnel. Journal of Facilities. 20 (13/14): 406-413. 